American Medical Journal 3 (2): 183-193, 2012

ISSN 1949-0070

C 2012 Science Publications

\title{
Paleolithic-Style Diet and Coronary Artery Disease: The Tissue is the Issue?
}

\author{
${ }^{1}$ Eri Toda, ${ }^{2}$ Takahashi Toru, ${ }^{3}$ R.B. Singh, ${ }^{4}$ Shaan E. Alam, \\ ${ }^{3}$ Fabien De Meester, ${ }^{3}$ Agnieszka Wilczynska and ${ }^{5}$ Douglas Wilson \\ ${ }^{1}$ Department of Cardiology, \\ Tokai University Hachioji Hospital, Tokyo, Japan \\ ${ }^{2}$ Department of Nutrition, Graduate School of Human Environment Science, \\ Fukuoka Women's University, Japan \\ ${ }^{3}$ The Tsim Tsoum Institute, Krakow, Poland \\ ${ }^{4}$ University College of Medical Sciences, New Delhi, India \\ ${ }^{5}$ Fellow Wolfson Research Institute, \\ School of Medicine Pharmacy and Health, Durham University, UK
}

\begin{abstract}
Approach: While the Western diet is proatherogenic, Paleolithic-style diet may be protective against Cardiovascular Diseases (CVDs). Results: Western diet is characterized with energy dense, refined, foods with a high glycemic index (e.g., refined starches; biscuits and bread) and unhealthy lipids (e.g., trans fats, saturated fat, omega-6 rich oils) poor in omega-3 fatty acids, phytochemicals and fibre. These diets are known to predispose inflammation and the epidemic of NonCommunicable Diseases (NCDs). CVD, diabetes mellitus, obesity, cancer and depression, are associated with increased production of Thromboxane A2 (TXA2), leucotrienes, prostacyclin, interleukins-1 and -6, tumor necrosis factor-alpha and C-reactive proteins in the tissues. Increased dietary intake of omega- 6 fatty acids is known to enhance all these biomarkers which have adverse pro-inflammatory effects resulting in to CVDs. Functional food approaches including consumption of a Mediterranean diet rich in fruits, vegetables, nuts, canola oil, olive oil characterized with low omega6/omega-3 ratio in the diet, as well as physical activity and meditation can modulate inflammation as well as body-mind interactions and may be protective against risk of CVD and all-cause mortality. Conclusion: Inflammation appears to be an important unifying hypothesis. In the absence of inflammation in the tissues, total cholesterol and other lipids may have neutral effects in the arterial tissues and myocardium. Therefore, the tissue is possibly the main issue for treatment.
\end{abstract}

Key words: Non-Communicable Diseases (NCDs), Cardiovascular Disease (CVD), Alpha-Linolenic Acid (ALA), Coronary Artery Disease (CAD), Saturated Fatty Acids (SFA)

\section{INTRODUCTION}

The focus of this review is based on the following premises and evidence, viz. (a) apparently nonsignificant evolutionary change in human genetic composition, that shaped human needs, over several recent millennia, (b) the dietary advice given by ancient Eastern physicians for the prevention of atherosclerosis and heart attacks, (c) the generally adverse dramatic change in dietary composition in modern times, presumably affecting gene regulatory mechanisms, giving rise to cardiovascular and related diseases that is supported by epidemiological and clinical trial evidence, (d) that the brain-body (liver, heart and gut axes), i.e., mind-body interactions play an important role in the genesis of proinflammatory responses (Takahashi et al., 2012) that a higher blood omega6/omega-3 fatty acid ratio may adversely change membrane structures and associated signalling mechanisms. The cumulative evidence behind this review suggests that it is the latter point which merits further, perhaps novel, research on membranes structures in relevant end-organs. All these issues are discussed below.

The diets of Homo sapiens was characterized with natural foods; fruits, vegetables, green leaves, seeds, eggs, fish, meat from running animals and honey during the Paleolithic period (Eaton et al., 1988; 1998). These foods were also available to pre-agricultural humans which shaped modern human's genetic nutritional

Corresponding Author: Eri Toda, Department of Cardiology, Tokai University Hachioji Hospital, Tokyo, Japan 
requirement (Simopoulos, 2003; 2009; Meester, 2008; 2009). Cereal grains (refined) and vegetable oils that are rich in omega- 6 fatty acids and trans fats and low in amino acids are relatively recent addition to the human dietary patterns that represent dramatic departure from those foods and nutrients to which we are adapted (Simopoulos, 2003; 2009; Meester, 2008). Early man also had enormous physical activity without any mental stress. The role of fatty acids, essential and nonessential amino acids, antioxidants and vitamins in the prevention and pathogenesis of Cardiovascular Diseases (CVD), type 2 diabetes and insulin resistance are well known (Esposito and Glugliano, 2006; Katcher et al., 2008; Meester, 2009; Fung et al., 2009). There is evidence that the Mediterranean diet which has similarity with Paleolithic diet can influence brain function related to gut-liver-brain-heart axis indicating its influence on mind-body connection (Singh et al., 2008; Wang et al., 2008; Singh et al., 2011a; Wilson et al., 2011).

There have been marked changes in the food supply with the development of agriculture about 10,000 years ago from now. However, only a nonsignificant change in our genes occurred during the past 10 centuries, due to the presence of omega- 3 fatty acids, amino acids, vitamins and antioxidants in the diet. However, now humans appear to live in a nutritional environment which completely differs from that for which our genetic constitution was selected (Eaton et al., 1988, 1998; Simopoulos 2003; Meester, 2008; 2009). Food consumption patterns have changed significantly during the last $100-160$ years, causing increased intake of Saturated Fatty Acids (SFA), trans fat, refined carbohydrates and linoleic acid and decrease in omega-3 fatty acids, from grain-fed cattle, tamed at farm houses, rather than meat from running animals. In South East Asia, 60\% of the mortality occurs due to Non-Communicable Diseases (NCDs) where diet and lifestyle may be responsible for these deaths (Dans et al., 2011). Apart from hyperlipidemia and hyperglycemia, oxidative stress and inflammation appear to be important mechanisms in the pathogenesis and prevention of diet related NCDs (Singh et al., 1992a; Esposito et al., 2004; Vogel, 2006; Singh et al., 2009).

Adverse effects of the diet were known to Indians from the ancient times, which are evident from the following verse from an ancient scripture Bhagwatgeeta (Bhagavad-Gita, 1998). "Foods which are bitter, acid, salted, burnt, fried and pungent, give rise to pain, mental stress and diseases" (3100 BC). Charaka (600 $\mathrm{BC})$, a great physician of India, knew about the role of diet and lifestyle in the pathogenesis of heart attack, which would be clear from the following verse. "Heart attack is born by the intake of fatty meals, overeating, excess of sleep, lack of exercise and anxiety", Charaka Sutra, 600BC.

Sushruta (600 BCE) (Bhishagratna, 2006) who was a surgeon from Vishwamitra family, gave a more clear description of atherosclerosis or madroga; "Excess intake of fatty foods and lack of exercise causes obesity and narrowing of the channels taking blood to the heart. It is useful to use googol, triphala and silajit in the treatment". These herbs are known to have high content of antioxidant flavonoids, vitamins and minerals as well as fibres.

About 2000 years ago (1st century), Confucius (Hsu, 1974), the Chinese philosopher taught his students, "the higher the quality of foods, the better and never rely upon the delicacy of cooking". Thus a dietary guideline based on experience, observation and thinking was given as; "cereals the basic, fruits the subsidiary, meat the beneficial and vegetable the supplementary". Therefore, according to WHO experts (Anon, 1990), the concept of eating, a diet high in animal foods and preference for meat and greasy foods was shaped in China.

However, possibly the meat was rich in omega-3 fatty acids without any trans fat and w-6 fat and the total fat intake remained within desirable limits and was not excessive as in the West. Therefore, this advice by the Chinese thinker appears to be profound.

Food and nutrient intake during Paleolithic period: The food and nutrient intake among hunter-gatherers and among Western and Asian populations show marked reduction in the consumption of omega-3 fatty acids, vitamins, antioxidants and amino acids and significant increase in the intakes of carbohydrates, (mainly refined), fat (saturated, trans fat and linoleic acid) and salt compared to the Paleolithic period (Tables 1-5). The protein or amino acid intake was 2.5 fold greater (33 vs. 13\%) in the Paleolithic diet compared to modern diet (Table 3). Approximately 10,000 years ago, prior to the Agricultural Revolution, our diet was based on an enormous variety of wild plants. However, today about $17 \%$ of plant species provide $90 \%$ of the world's food supply which is mainly contributed by grains. Wheat, corn and rice account for three fourths of the world's grain production on which humans are dependent for food supply. Grains are high in omega- 6 fatty acids and carbohydrates and low in omega-3 fatty acids and antioxidants compared to leafy green vegetables. Eaton and co-workers (Eaton et al., 1988; 1998) have estimated higher intakes for protein, calcium, potassium 
Am. Med.J. 3 (2): 183-193, 2012

and ascorbic acid and a lower intake of sodium in the diet of the late Paleolithic period than the current diets in the developed and developing countries. Green leafy vegetables are also rich sources of antioxidants, magnesium, omega- 3 fatty acids and carotenoids. These appear to be high in the Paleolithic diet. The proteins which were from both animal (running animals and eggs) and plant sources (green leaves and seeds), should have been composed of both essential and nonessential amino acids (Table 1 and 3 ).

Fatty acids in the diet and development of CVDs and diabetes: There has been an enormous increase in omega- 6 fatty acid (about $30 \mathrm{~g} \mathrm{day}^{-1}$ ) in the diet due to the production of oils from vegetable seeds such as corn, sunflower, sai flower, soybean and cotton. Increased intake of meat has resulted in greater intake of arachidonic acid $\left(0.2-1.0 \mathrm{mg}\right.$ day $\left.^{-1}\right)$, whereas the consumption of Alpha-Linolenic Acid (ALA) has decreased (about $0.55 \mathrm{~g} \mathrm{day}^{-1}$ ) and the amounts of Eicosapentaenoic Acid (EPA) and Docosahexaenoic Acid (DHA) are 48 and $72 \mathrm{mg}$ day $^{-1}$ respectively (Table 4-6). A relative and absolute decrease in omega-3 fatty acids has led to an imbalance and increase in the ratio of omega-6/omega-3 fatty acids to up to 50 in South Asia and other developing countries, consuming vegetable seed oils (corn, soyabean, saiflower, sunflower, cotton) (Lorgeril et al., 1994; Singh et al., 2002; Harper and Jacobson, 2005; Gal et al., 2008; Solfi et al., 2010). Saturated Fatty Acids (SFA) and Trans Fatty Acids (TFA) elevate, PUFA decrease and mono-unsaturated fats MUFAs have beneficial effects on total and low Density Lipoprotein Cholesterol (LDL) as well as on HDL cholesterol. Omega-6 PUFA and TFA also decrease HDL cholesterol and increase insulin resistance, free radical stress and inflammation, which may enhance atherosclerosis (Lorgeril et al. 1994; Singh et al. 2002; Harper and Jacobson, 2005). Increased intake of total fat, TFA, SFA and omega- 6 fatty acids and refined carbohydrates, may cause insulin resistance resulting in metabolic syndrome (Meester, 2008; Singh et al. 2008). Decreased intake of MUFA (Singh et al., 1996; 1999; 2000; Aratti et al., 2004), omega-3 fatty acids (Singh et al., 2011c; Pella et al., 2003; Simopoulos 2003; Kartikey et al., 2010), fibre and phytochemicals, may enhance the metabolic syndrome, leading to CVDs and other chronic diseases (Lorgeril et al., 1999; Kang et al., 2004; Iso et al., 2006; Meester, 2009; Eaton, 2009).
Table 1: Food and nutrient intake among hunter-gatherer and Western populations

\begin{tabular}{llll}
\hline Food and nutrient & Hunter-gatherer & Western population Asians \\
\hline Energy density & Low & High & Low \\
Protein & High & Low-moderate & Low \\
Animal & High & Low -moderate & Low \\
Vegetable & Very low & Low -moderate & Low \\
Carbohydrate & Low-moderate & Moderate- & High-slow \\
& (slowly absorbed) & rapidly absorbed & \\
Fibre & High $(>30 \mathrm{~g})$ & & High \\
Fat & Low & Low $(<15 \mathrm{~g})$ & Low \\
Animal & Low & High & Low \\
Vegetable & Very low & High & High \\
Total omega-3 & High $(2.3 \mathrm{~g} /$ day) & Low $(0.2 \mathrm{~g} /$ day) & $0.5-0.85 \mathrm{~g}$ \\
Ratio omega-6:omega-3 3 High & Low 2.4 & High $15-20$ & $25-50$ \\
Vitam & & low & moderate
\end{tabular}

Vitamins and minerals

Note: Modified from Eaton et al., 1998 and Singh et al. (2011c), references, $1,2,44$

Table 2: Estimated fatty acid consumption in the late Paleolithic period

\begin{tabular}{ll}
\hline $\begin{array}{l}\text { Sources } \\
\text { Plants }\end{array}$ & $\begin{array}{l}\text { Fatty acids (g/day) } \\
\text { en } 35.65 / \text { day }\end{array}$ \\
\hline Linoleic acid & 4.28 \\
Alpha-linoleic acid & 11.4 \\
Animal & 4.56 \\
Linoleic acids & 1.21 \\
Alpha-linolenic acid & \\
Total & 8.84 \\
Linoleic acid & 12.6 \\
Alpha linolenic acid & \\
Animal & 1.81 \\
Arachidonic acid(omega-6) (AA) & \\
Long chain omega-3 fatty acids & 0.39 \\
Eicosapentaenoic acid(omega-3)(EPA) & 0.12 \\
Docosatetraenoic acid(omega-6) (DTA) & 0.42 \\
Docosapentaenoic acid(omega-3)(DPA) & 0.27 \\
Docosahexaenoic acid(omega-3)(DHA) & 1.20 \\
Total long chain omega-3 fatty acids & 0.70 \\
Ratios of omega-6/omega-3 & 1.79 \\
Linoleic acid/alpha linolenic acid+ & \\
AA+DTA/EPA+DPA+DHA & 0.77 \\
Total omega-6/omega-3 & 4
\end{tabular}

Note: Modified from Eaton et al. (1998) ref 4 and Singh et al. (2011b), Ref 6

Table 3: Nutrient composition in the late Paleolithic and current recommendations

\begin{tabular}{lll}
\hline $\begin{array}{l}\text { Nutrient } \\
\text { per day }\end{array}$ & $\begin{array}{l}\text { Late } \\
\text { Paleolithic }\end{array}$ & $\begin{array}{l}\text { Current } \\
\text { recommendation }\end{array}$ \\
\hline Total dietary energy $\%$ & & \\
Protein & 33 & 12 \\
Carbohydrate & 46 & 58 \\
Fat & 21 & 30 \\
Alcohol & 0 & moderate alcohol \\
P/S ratio & 1.41 & 1 \\
Cholesterol, mg & 520 & 300 \\
Fibre, g & $100-150$ & $30-60$ \\
Sodium,mg & 690 & $1100-3300$ \\
Calcium, mg & $1500-2000$ & $800-1600$ \\
Ascorbic acid, mg & 440 & 60
\end{tabular}

Note: Modified from Eaton et al., 1988 their references 1, 2 and Singh et al., 2011c, their references 1,2,46 
Am. Med.J. 3 (2): 183-193, 2012

Table 4: Ethnic differences in fatty acid levels in thrombocytes phospholipids and percentage of all deaths from cardiovascular disease

\begin{tabular}{llll}
\hline \multicolumn{1}{c}{ cardiovascular disease } & & \\
& $\begin{array}{l}\text { Europe and } \\
\text { USA \% }\end{array}$ & $\begin{array}{l}\text { Japan } \\
\%\end{array}$ & $\begin{array}{l}\text { Greenland } \\
\text { Eskimos \% }\end{array}$ \\
\hline Arachidonic acid(20:4w6) & 26 & 21 & 8.3 \\
Eicosapentaenoic acid(20:5omega-3) & 0.5 & 1.6 & 8 \\
Ratio of omega-6/omega-3 & 50 & 12 & 1 \\
Mortality from & 45 & 12 & 7 \\
cardiovascular disease & & & \\
\hline
\end{tabular}

Note: Modified from Singh et al., 2011b, their references 1,2,44

Table 5: Fatty acids ratio in the diets

\begin{tabular}{lll}
\hline Subjects & Omega-6/omega-3 & \\
\hline Paleolithic & 0.79 & Estimated \\
Greece prior to 1960 & $1.00-2.00$ & Current 7.10 \\
Japan & 4 & Early 1-2 \\
India, rural & $5-6.1$ & Prior to 1960, 3-4 \\
India urban & $38-50$ & Prior to 1960, 5-10 \\
UK & 15 & Prior to 1960,10.00 \\
Northern Europe & 15 & Prior to 1960,10.00 \\
USA & 16.74 & Prior to 1950 7-8 \\
Eastern Europe & $20-25$ & Estimated \\
Indian hunter-gatherers & $1.00-2.00$ & Estimated \\
\hline
\end{tabular}

Note: Modified from Singh et al., 2011b, their references 1,2,44

Effect of Paleolithic-style diet on coronary artery disease: Recent studies indicate that a prudent dietary pattern, similar to a Mediterranean-style diet (Singh et al., 1992a; Renaud et al., 1995; Trichopoulou et al., 2003; Esposito et al. 2004; Knoops et al., 2004; He et al., 2007) may be protective against NCDs; cardiovascular diseases (Vogel, 2006; Heidemann et al., 2008; Singh et al., 2009), hypertension (McCall et al., 2009; Singh et al., 2011c), coronary artery diseases and stroke (Fung et al., 2008), metabolic syndrome (Esposito and Glugliano 2006; Katcher et al. 2008), myocardial infarction (Gramenzi et al., 1990; Singh et al., 2006; 2009; Iqbal et al., 2008), type 2 diabetes, osteoporosis and degenerative diseases of the brain. Further studies showed that a fruit and vegetable enriched diet can protect against myocardial infarction and modulate microvascular function (McCall et al., 2009). The beneficial effects of the Paleolithic prudent dietary pattern may be because of low omega- 6 fatty acids and high content of AlphaLinolenic Acid (ALA), antioxidants, flavonoids, vitamins and carotenoids present in the diet. Omega-3 fatty acids, such as ALA, is rich in mustard oil, walnuts, green leaves, whole grains and seeds and EPA and DHA are rich in fish and fish oil and can protect against ventricular premature beats and myocardial infarction (Harper and Jacobson, 2005; Harris et al., 2007; Campos et al., 2008). Randomized, controlled intervention trials (Singh et al., 1992b; 1992c; 2002; 2011c; Sofi et al., 2010;) also confirm that a Paleolithic style diet can cause significant decline in morbidity and mortality due to cardiovascular events which may be because of the ALA present in such a diet (Lorgeril et al., 1994; Gal et al., 2008).

These findings need re-emphasis because of new research evidence showing multiple functions of
Paleolithic-style diet on cardiovascular functions and NCDs. Several of these studies were conducted when thrombolysis and angioplasty were not freely available for the treatment of Acute Coronary Syndrome (ACS) (Singh et al. 1992b; 1992c). Therefore it is not possible to conduct such studies again to demonstrate the role of diet in the prevention of ACS, although the present authors (Singh et al., 1995; 2011b; 2011c) and many other agencies now advise increased intake of fruits and vegetables for the prevention of CVDs (Anon 1988; 1990; 1991). A recent study reported that one micro RNA in particular, MIR 168a, which is highly enriched in rice, was found to inhibit a protein that helps remove Low-Density Lipoprotein (LDL) from the blood, suggesting that microRNAs can influence gene expression across kingdoms (Zhang et al., 2011). Diet can also provide beneficial or adverse effects by its influence on gut-brain-liver axis leading to increase or decline in CVDs (Gal et al., 2008; Wang et al., 2008). These gut-brain-liver studies and others (Pella et al., 2003; Simopoulos, 1999); Kang et al 2004; Meester, 2009; Eaton, 2009; Singh et al., 2010; Kartikey et al., 2010). There is an experimental study which showed that increased availability of omega- 6 fatty acid in the tissues, enhances the formation of omega- 3 fatty acids by the animals due to extraordinary capability of the animals to fight the adverse effects of omega- 6 fatty acids (Kang et al., 2004).These studies, further emphasize that it is the tissue which is the main issue rather than associated risk factors for CVDs and other NCDs.

Epidemiological studies: Epidemiological studies indicate that a prudent dietary pattern characterized by fruit, vegetable, legume and whole grain intake appears to be protective. The protective effects of prudent dietary patterns appear to be due to a low omega6/omega-3 ratio of such diets because Western diet and South Asian diets have high omega-6/omega-3 ratio of 20-50 as shown in recent studies (Pella et al., 2003; Meester, 2009; Eaton, 2009; Kartikey et al., 2010; Singh et al., 2011d). The INTERHEART study, involving participants from 52 countries (Iqbal et al., 2008) examined the relationship between dietary patterns and risk of Acute Coronary Syndrome (ACS). Consistent with previous studies in single withinpopulation cohort studies, the authors found an inverse association between the prudent pattern score and risk of ACS and a significant positive association between the Western pattern score and increased risk of ACS. No association of Oriental diet with risk of ACS was reported. A dietary risk score based on 7 food items on the food-frequency questionnaire (meat, salty snacks, fried foods, fruits, green leafy vegetables, cooked vegetables and other raw vegetables) was constructed by the authors. The investigators found that a higher score, indicating a poor diet was strongly associated 
with ACS risk and the subjects in the highest quartile of the score had nearly a 2-fold increased risk, even after adjustment for established coronary risk factors. On the basis of an arbitrary cut point of the score (top 3 quartiles versus the bottom quartile), the investigators estimated that $30 \%$ of Myocardial Infarction (MI) could be explained by unhealthy diets worldwide. The INTERHEART study is the first large study to quantify eating patterns in all geographic regions of the world. It provides evidence that despite different food habits in various populations, reproducible patterns can be found in diverse regions of the world. These findings are important because there has been a concern that dietary patterns derived through a data-driven approach such as Principal Components Analysis may be highly unstable and non-reproducible because of very different eating habits in different populations.

In a large, prospective, observational study (Heidemann et al., 2008) involving 72, 113 female nurses who were free of Coronary Artery Disease (CAD), stroke, diabetes and cancer, Factor Analysis identified 2 dietary patterns from data collected using serial food frequency questionnaires. One pattern, called prudent, was characterized by a high consumption of vegetables, fruit, legumes, fish, poultry and whole grains. The other pattern, called Western, corresponded to a high consumption of red meat, processed meat, refined grains, french fries, sweets and desserts. Individuals were classified by their level of adherence to both the prudent diet and the Western diet. After baseline data collection in 1984, follow-up lasted 18 years, during which time 6011 deaths occurred (3319 [52\%] as a result of cancer; 1154 (19\%) resulting from Cardiovascular Disease (CVD); and 1718 (29\%) resulting from other causes). There was a $17 \%$ lower risk of total mortality among those who were most adherent to the prudent diet (highest versus lowest quintile of adherence), a $28 \%$ lower risk of CVD mortality and 30\% lower mortality from non-CVD, non-cancer causes. Cancer was not associated with the inverse prudent dietary pattern. A comparison of the highest and lowest quintiles of adherence showed that consumption of the Western diet was associated with increased total mortality (21\%), CVD mortality (22\%), cancer mortality (16\%) and mortality from non-CVD, non-cancer causes (31\%). Hence, except for cancer, risk relationships for the prudent and Western dietary patterns appear to be the inverse of each other. Mortality thus was increased as adherence to the prudent diet decreased and adherence to the Western diet increased. In one cross-sectional survey of 6940 subjects, above 25 years of age, fruit, vegetable and legume intake were inversely associated with risk of pre-hypertension and hypertension in five Indian cities (Singh et al., 2011c).

A meta-analysis of cohort studies, quantitatively assessed the relation between fruit and vegetable intake and incidence of CAD which reported Relative Risks (RRs) and corresponding 95\% Confidence Interval (CI) of CAD with respect to frequency of fruit and vegetable intake (He et al., 2007). A total of 278459 subjects (9143 CAD events) were included, with a median follow-up of 11 years. The individuals who had less than 3 servings/day of fruit and vegetables, the pooled RR of CAD was 0.93 (95\% CI: 0.86-1.00, p = 0.06) while those with more than 5 servings/day, the RR was $0.83(0.77-0.89, \mathrm{p}=0.0001)$. This meta-analysis of prospective cohort studies demonstrated that increased consumption of fruit and vegetables, less than 3 to more than 5 servings/day is related to a $17 \%$ reduction, whereas increased intake to 3-5 servings/day is associated with a smaller and borderline significant reduction in CAD risk. These results provide evidence supporting that 5 or more servings per day of fruit and vegetables, are needed to protect from CVD.

Table 6: Effect of omega-3 fatty acid rich Paleolithic-style diet in patients with acute myocardial infarction

\begin{tabular}{|c|c|c|c|c|}
\hline \multirow[b]{2}{*}{ Foods and nutrients } & \multicolumn{2}{|c|}{ Paleolithic-style diet group $(n=204)$} & \multicolumn{2}{|c|}{ Standard diet group $(\mathrm{n}=202)$} \\
\hline & 4-7 days & After 1 years & 4-7 days & After 1 years \\
\hline Fruits and vegetables (g. day ${ }^{-1}$ ) & $508.4(28.66) * *$ & $575(91.4) * *$ & $254.4(17.2)$ & $220.5(19.6)$ \\
\hline Potato, radish, & $60.5(6.8)$ & $115(12.7) * *$ & $72.0(12.5)$ & $155.6(32.5)$ \\
\hline Legumes and pulses (g. Day ${ }^{-1}$ ) & $80.5(6.6) * *$ & $95.0(8.9) * *$ & $52.5(4.6)$ & $45.6(5.6)$ \\
\hline Almonds and walnuts (g. Day ${ }^{-1}$ ) & $82.4(5.7) * *$ & $75.5(5.2) * *$ & - & - \\
\hline Fish $\left(\right.$ g. Day- $\left.{ }^{-1}\right)$ & $52.5(6.5) * *$ & $22.4(4.1) * *$ & $20.2(3.1)$ & $10.5(3.5)$ \\
\hline Chicken (g. Day ${ }^{-1}$ ) & - & $10.2(3.2)^{*}$ & $76.2(6.5)$ & $66.5(10.5)$ \\
\hline Mustard or soybean oil & $18.4(3.9)^{*}$ & $31.5(5.5) * *$ & $10.5(2.3)$ & $6.8(2.8)$ \\
\hline Butter or clarified butter (g. Day ${ }^{-1}$ ) & $2.5(0.6) * *$ & $3.3(0.71)^{*}$ & $10.5(2.6)$ & $12.6(3.5)$ \\
\hline Skim milk $\left(\mathrm{ml} \mathrm{day}^{-1}\right)$ & $161.2(12.0)$ & $152(14.5)^{*}$ & $150.2(8.0)$ & $165.5(16.1)$ \\
\hline Wheat chapatti & $5.5(1.6) * *$ & $30.6(5.5)$ & $50.6(6.6)$ & $55.6(7.8)$ \\
\hline Bread, biscuits (g. Day ${ }^{-1}$ ) & $10.6(2.2)^{*}$ & $25.5(6.2) * *$ & $230.6(20.1)$ & $212.2(18.1)$ \\
\hline Rice and wheat cereals $\left(g_{\text {. Day }}{ }^{-1}\right)$ & $25.6(2.4)$ & $30.6(5.5)$ & $30.2(3.1)$ & $35.6(4.8)$ \\
\hline Honey or raisins (g. Day ${ }^{-1}$ ) & $2.6(0.8)$ & $5.5(1.2)$ & - & - \\
\hline Sugar $\left(\right.$ g. Day $\left.{ }^{-1}\right)$ & $16.4(3.7)^{*}$ & $12.6(3.4)^{*}$ & $25.5(5.4)$ & $30.5(7.6)$ \\
\hline Total Adherence score (\%) & $65.2(17.2)$ & $63.9(14.8)$ & $123.0(30.0)$ & $71.0(30.0)$ \\
\hline Total foods, & $1027(232)$ & $1184.6(254)$ & 983.4(213) & $862(204)$ \\
\hline
\end{tabular}


Am. Med.J. 3 (2): 183-193, 2012

Table 7: Fatty acid consumption in the Paleolithic-style diet group and standard diet group

\begin{tabular}{|c|c|c|c|c|c|}
\hline \multirow[b]{2}{*}{ Fatty acid $\mathrm{KJ} /$ day } & \multirow{2}{*}{$\begin{array}{l}\text { Before entry } \\
\text { All patients } \\
(\mathrm{n}=406)\end{array}$} & \multicolumn{2}{|l|}{ At entry } & \multicolumn{2}{|c|}{ After one year } \\
\hline & & $\begin{array}{l}\text { Paleolithic } \\
(\mathrm{n}=204)\end{array}$ & $\begin{array}{l}\text { Standard } \\
(n=202)\end{array}$ & $\begin{array}{l}\text { Paleolithic } \\
(\mathrm{n}=204)\end{array}$ & $\begin{array}{l}\text { Standard } \\
(\mathrm{n}-202)\end{array}$ \\
\hline Saturated & $10.0(0.39)$ & $7.0(0.22)$ & $10.0(0.38)$ & $7.2(0.24)$ & $10.8(0.36)$ \\
\hline Monounsaturated & $9.3(0.38)$ & $9.5(0.37)$ & $7.6(0.26)$ & $8.0(0.35)$ & $10.2(0.32)$ \\
\hline Polyunsaturated & $6.7(0.30)$ & $8.1(0.44)$ & $6.5(0.39)$ & $8.6(0.39)$ & $7.0(0.26)$ \\
\hline omega-6 & $6.5(0.29)$ & $6.3(0.28)$ & $6.3(0.29)$ & $7.0(0.36)$ & $6.2(0.24)$ \\
\hline omega-3 & $0.2(0.07)$ & $1.8(0.13)^{* * *}$ & $0.2(0.082)$ & $1.6(0.12)^{* *}$ & $0.3(0.083)$ \\
\hline omega-6/omega-3 ratio & $32.5(3.3) * *$ & $3.5(0.76)^{* *}$ & $31.5(2.4)$ & $4.4(0.56)^{* *}$ & $20.6(2.1)$ \\
\hline Main dietary oil & Pea nut & Mustard & Sunflower & Mustard & Sunflower \\
\hline
\end{tabular}

Note: Values are mean \pm (Standard deviation) ${ }^{* *}=\mathrm{p}<0.01$, Singh et al., 2012, their reference 40

Dietary-patterning analysis has been increasingly used recently, as an alternative method to traditional single-nutrient analysis because it can assess cumulative effects of the overall nutrients in the diet. Habitual intake patterns are typically quantified by statistical methods such as Factor or Cluster Analysis or dietquality indexes based on prevailing dietary recommendations or healthful traditional diets e.g., the Mediterranean diet (Renaud et al., 1995; Lorgeril et al., 1994; Sofi et al., 2010), the Japanese diet (Iso et al., 2006) and the Indo-Mediterranean diet (Singh et al., 2002; Pella et al., 2003). Principal Components Analysis is commonly used to define dietary patterns using food consumption information to identify common underlying dimensions (factors or patterns) of food intake. The method aggregates specific food items based on the degree to which these food items are correlated with each other. A summary score for each pattern is then derived and can be used to examine relationships between various eating patterns and outcomes of interest such as CAD, diabetes mellitus, stroke and other chronic diseases. Earlier validation studies found that 2 major patterns (the prudent and Western patterns) identified through Principal Components Analysis of food consumption data assessed by food frequency questionnaires were reproducible over time and correlated reasonably well with the patterns identified from diet records. The consistent association observed between the Western or unhealthy dietary pattern (high in animal products, salty snacks, refined starches and sugar and fried foods and low in fruits and vegetables) and ACS risk in different regions of the world from the INTERHEART study and other studies as well as in our study, provide consistent evidence of the adverse effects of globalization on human nutrition and chronic disease risk. However, this evidence is indirect because these studies did not specifically assess the impact of global trade and marketing on food consumption patterns across different countries (Renaud et al., 1995; Knoops et al., 2004; He et al., 2007; Heidemann et al. 2008; Hu et al. 2008; Iqbal et al., 2008; Singh et al., 2011c). Despite this weakness, most recent studies suggest that the current trend of dietary convergence toward a typical Western diet characterized by high omega-6/omega-3 ratio of fatty acids is likely to play a role in the globalization of obesity, CVD, diabetes and cancer.

Intervention trials on low omega-6/omega-3 fatty acid ratio Paleolithic-style diet and mortality: Cohort studies provide an association of diet with risk of CVDs and deaths. However, randomized, controlled intervention trials are necessary to provide a scientific proof that diet has a role in the prevention of CVDs (Singh et al., 2002; Gal et al., 2008; Sofi et al., 2010). Intervention trials, using the whole diet approach so far produced are also in line with this epidemiological evidence. The effect of Paleolithic-style diet was examined in patients $(\mathrm{n}=204$ intervention group, $\mathrm{n}=$ 202 control group) with acute coronary syndromes, which showed significant decline in total cardiac events as well as in total mortality after 6 weeks and the benefit continued after one year (Singh et al., 1992b; 1992c). Further follow up for 2 years in this study (Singh et al., 2012) is different from the published work, because its emphasis is on the Paleolithic dietary patterns and ALA content of the diet to be responsible for the significant greater survival in the intervention group compared to control group (Table 6 and 7). Dietary patterns before entry to the study showed a higher omega-6/omega-3 ratio of 32.5 in the diets of both the groups. Intervention group A was advised a Paleolithic style diet with omega6/omega-3 fatty acid ratio of 4.3 compared to standard diet group with ratio of 20 (Table 6 and 7). After a follow up of 2 years, total mortality was significantly declined in the Paleolithic style diet group compared to control group as shown in Fig. 1 for the intervention group compared to control group $(85.3 \%$ vs. $74.8 \%, \mathrm{p}<0.001)$. The mortality was lowest among subjects with omega6/omega-3 ratio of less than 10 which showed graded increase with increase in the fatty acid ratio in both the groups as shown in Fig. 2.

In the Lyon diet heart study 605 patients who had a myocardial infarction were randomly assigned to a 'Mediterranean-style' diet or a control diet resembling the American Heart Association Step I diet. 
Table 8: Total cardiovascular events in the Paleolithic-style diet and control group

\begin{tabular}{lll}
\hline Data & $\begin{array}{l}\text { Indo-Mediterranean } \\
\text { diet }(\mathrm{n}=499)\end{array}$ & $\begin{array}{l}\text { Standard Diet } \\
(\mathrm{n}=501)\end{array}$ \\
\hline Non fatal myocardial infarction & $21(4.2 \%)^{*}$ & $43(8.6 \%)$ \\
Fatal myocardial infarction & $12(2.4 \%)$ & $17(3.4 \%)$ \\
Sudden cardiac death & $6(1.2 \%)$ & $16(3.2 \%)$ \\
Total cardiac events & $39(7.8 \%)^{* *}$ & $76(15.2 \%)$ \\
Stroke & $7(1.4 \%)$ & $13(2.6 \%)$ \\
Stroke death & $2(0.4 \%)$ & $3(0.6 \%)$ \\
Total cardiovascular events & $48(9.6 \%)^{* *}$ & $92(18.3 \%)$ \\
Total deaths & $24(4.8 \%)$ & $38(8 \%)$ \\
\hline
\end{tabular}

Note: Values are number $(\%), *=\mathrm{p}<0.01, * *=\mathrm{p}<0.001$, Singh et al. (2002), their references 35,50

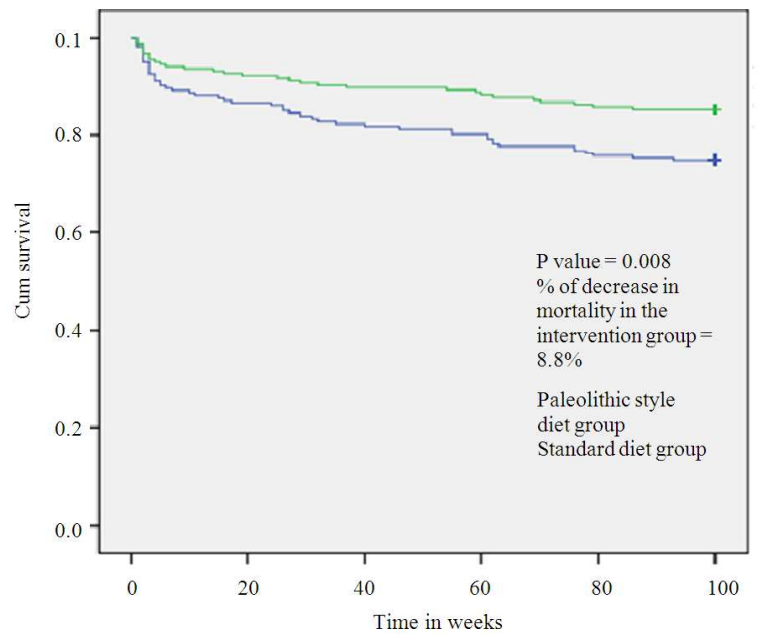

Fig. 1:Kaplan Meier survival curves: proportions of deaths after 2 years of either standard or Paleolithic-style diet: Singh et al., 2012

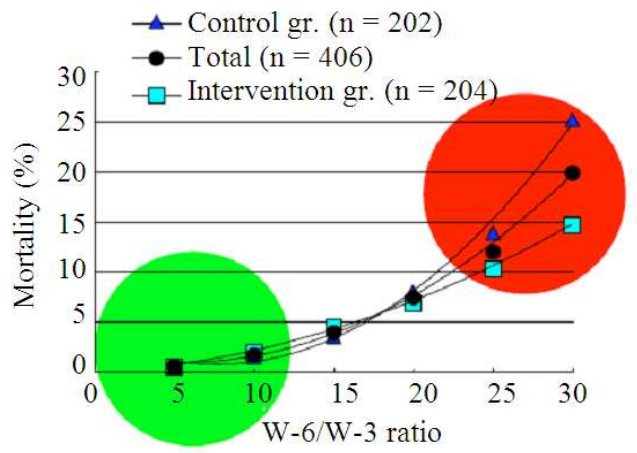

Association of W-6/W-3 ratio of fatty acids with mortality

Fig. 2:Low (green) and high (red) between-group differential mortality risk based on omega6/omega-3 ratios. Data from Singh et al., 2012

The Mediterranean diet model supplied 30\% of energy from fats and $<10 \%$ of energy from saturated fatty acids, whereas the intake of 18:3 (n-3) ( $\alpha$-linolenic acid) provided $>0.6 \%$ of energy. After a mean follow- up of 27 months, the risk of new acute myocardial infarction and episodes of unstable angina was reduced by about $70 \%$ by the Mediterranean diet. Moreover, total mortality was also reduced by $70 \%$. Long-term follow up for 4 years also showed that the beneficial effects of diet were continued.

Singh et al., 2002 tested an 'Indo-Mediterranean diet' in 1000 patients in India, with existing coronary disease or at high risk for coronary disease. Half of the patients ( $n=499$ vs. 501 ) were administered a diet rich in fruits, vegetables, whole grains, walnuts, mustard and soy bean oil as a source for omega- 3 fat and the rest (501) patients were advised to take prudent diet advised by the National Cholesterol Education Program step 1 diet in 1988 (Anon 1988). At the end of 2 year follow up, the Paleolithic-style diet group consumed significantly more fruits, vegetables and legumes than did the control group $\left(537 \pm 127\right.$ vs. $231 \pm 19 \mathrm{~g}$ day $^{-1}$, $\mathrm{p}<0.001)$ as well as more mustard and soy bean oil $\left(31 \pm 6.5\right.$ vs. $\left.15.2 \pm 5.5 \mathrm{~g} \mathrm{day}^{-1}\right)$. The mean intake of ALA was over two fold greater in the Paleolithic-style diet group compared to control group. ( $1.8 \pm 0.4$ vs. $0.8 \pm 0.2$ $\left.\mathrm{g} \mathrm{day}^{-1}, \mathrm{p}<0.001\right)$. The omega-6/omega-3 ratio of fatty acids was slightly higher at baseline in the intervention group than in the control group ( $39 \pm 12$ vs. $34 \pm 10)$ yet both these values are extremely high, reflecting a diet with a very high omega- 6 content yet low omega-3 (Pella et al., 2003). At the end of two years follow up, this ratio showed a marked decline in the intervention group, which was greater than that observed in the control group consuming control diet $(9.1 \pm 12$ vs. $21 \pm 10, p<0.001)$. The study endpoints were; significant decline in the total cardiac events, sudden cardiac death and non-fatal infarction in the intervention group compared to the control group (Table 8).

Esposito et al., 2004 randomized 180 patients (99 men, 81 women) with tmetabolic syndrome to a Mediterranean style diet, characterized with whole grains, vegetables, fruits, nuts and olive oil vs. a cardiac-prudent diet with fat intake $<30 \%$. After a follow up of 2 years, subjects in the intervention diet showed greater weight loss, had lower C-reactive protein and proinflammatory cytokine levels, had less insulin resistance, as well as lower total cholesterol and triglycerides and higher HDL cholesterol. The prevalence of metabolic syndrome was reduced to one half. The Japan Public Health Centre based study (Iso et al., 2006) showed that eating more omega-3 fatty acids by increased intake of fish was associated with significant reduction in cardiovascular disease and cardiac mortality. The diet and re-infarction trial (Burr et al., 1989) showed that modest intake of fish, 2 servings per week, can cause significant a decrease in total mortality and cardiovascular mortality. 
Since no benefit was observed in non-fatal infarction, the authors concluded that omega- 3 fatty acids may have prevented ventricular fibrillation by altering cardiomyocyte cell membrane phospholipids. There is experimental evidence indicating that the very long chain omega- 3 fatty acids in fish oil and fatty fish have an important effect on the pathogenesis of arrhythmias in the setting of myocardial ischemia and reperfusion both in-vivo and in-vitro (McLennan et al., 1988). There is additional evidence from other studies indicating the role of omega-6/omega-3 ratio of fatty acids in the pathogenesis of Non-communicable diseases (Endres et al., 1989; Kumar et al., 1992; Simopoulos, 1994; 2006; 2008; Appel, 2008).

There is clear evidence that dietary changes or omega-3 fatty acid supplementation and decrease in omega-6 fatty acid intake may induce a marked alteration in the omega-6/omega-3 fatty acid ratio in tissue. For example, a value of omega-6/omega-3 ratio of 1-2:1 has been shown to be the ratio found in the traditional diet of Cretans and it was this study that led to the concept of a Mediterranean diet and its relation to a Paleolithic-style diet discussed in this review. Consequently, the myocardial and arterial tissue may, through conditioning by the nutrients of a Paleolithicstyle diet, be protected against the otherwise proinflammatory risk of a generalized Western diet.

Several cohort studies and intervention trials suggest that increased consumption of functional foods like fruits, green leafy vegetables, nuts and legumes decreases the risk of CVD morbidity and mortality. Potentially protective contents of these foods include ALA, EPA, DHA, folate, magnesium, calcium, potassium, fibre, vitamin E, carotenoids, arginine, cysteine, oleate and favorable lysine to arginine and methionine to arginine ratios. These nutrients are important in the cardiomyocyte and arterial cell functions which are determinant of CVDs. The lysine to arginine ratio is potentially involved in atherogenesis and methionine to arginine ratio is important for endothelial function because arginine is the precursor of $\mathrm{NO}$ which protects the endothelium and methionine is the precursor of homocysteine that is known to cause endothelial damage. Folic acid is protective because it antagonizes the homocysteines.

Calcium/magnesium ratio indicating high magnesium is also protective to cardiomyocyte and endothelial cells. These findings indicate that it is the tissue which is the main issue in the pathogenesis and prevention of CVDs. If the tissue concentration of omega-6/omega-3 ratio is $1: 1$ along with other nutrients in proper ratio, high LDL cholesterol (unoxidised) would be neutral without any evidence of endothelial dysfunction. This concept has become more relevant because microRNA have been demonstrated in the blood and milk after feeding of rice to experimental animals (Zhang et al., 2011). Therefore, for prevention of CVDs, eat $400 \mathrm{~g} \mathrm{day}^{-1}$ of fruits, vegetables and nuts and another $400 \mathrm{~g} \mathrm{day}^{-1}$ of legumes and other whole grains along with $30-50 \mathrm{~g}$ of canola oilt olive oil to protect our tissues which is the major issue.

\section{CONCLUSION}

In summary, this review suggests that the prevention of CVDs can be substantially achieved by consuming a notional Paleolithic or Mediterraneanstyle diet such as the daily consumption of suitable proportions of fruit, vegetables and nuts, legumes and canola and olive oil. Furthermore, it has focused on the need for more research on membrane and signaling pathways in end-organ tissue and the brain.

Conflicts of interest: There are no declared conflicts of interest.

\section{ACKNOWLEDGEMENT}

The International College of Nutrition, International College of Cardiology and the Tsim Tsoum Institute provided logistic support to write this article.

\section{REFERENCES}

Anon, 1988. National cholesterol education program; report of the expert panel on detection, evaluation and treatment of high blood cholesterol in adults. Arch. Intern. Med., 148: 36-69.

Anon. 1990. World Health Organization; Diet, Nutrition and Prevention of Chronic Diseases. WHO, Geneva.

Anon. 1991. US Department of Agriculture and US department of Health and Human Services. Revised dietary Guidelines for Americans. 3rd Edn, Washington, Washington DC, US Department of Agriculture.

Appel, L.J., 2008. Dietary patterns and longevity. Circulation, 118: 214-15. DOI: 10.1161/ CIRCULATIONAHA.108.788497

Aratti, P., G. Peluso, R. Nicolai and M. Calvani, 2004. Polyunsaturated fatty acids: Biochemical, nutritional and epigenetic properties. J. Am. Coll. Nutr., 23: 281-302. PMID: 15310732

Bhagavad-Gita, T., 1998. Bhagavad-Gita: The threefold divisions of material existence. Chapter 17. V8-10.

Burr, M.L., A.M. Fehily and J.F. Gilbert, 1989. Effects of changes in fat, fish and fibre intakes on death and myocardial reinfarction: Diet And Reinfarction Trial (DART). Lancet, 30: 757-761. DOI: 10.1016/S0140-6736(89)90828-3 
Campos, H., A. Baylin and W.C. Willett, 2008. AlphaLinolenic acid and risk of nonfatal acute myocardial infarction. Circulation, 118: 339-345. PMID: 18606916

Dans, A., N. Ng, C. Verghese, E.S. Tai and R. Firestone et al., 2011. The rise of chronic non-communicable diseases in Southeast Asia. Time Action Lancet, 377: 680-689. PMID: 21269677

Lorgeril, M.D., S. Renaud, N. Mamelle, P. Salen and J.L. Martin et al., 1994. Mediterranean alphalinolenic acid-rich diet in secondary prevention of coronary heart disease. Lancet, 343: 1454-1459. PMID: 7911176

Lorgeril, M.D., P. Salen, J.L. Martin, I. Monjaud and J. Delaye et al., 1999. Mediterranean diet, traditional risk factors and the rate of cardiovascular complications after myocardial infarction. Final report of the lyon diet heart study. Circulation, 99: 779-785. PMID: 9989963

Meester, F.D., 2008. Wild-type Food in Health Promotion and Disease Prevention. The Columbus Concept (Eds.), Fabien De Meester, Ronald R. Watson, Wild Type Food in Health Promotion and Disease Prevention, Humana Press, Totova, NJ, ISBN-10: 1588296687, pp: 571.

Meester, F.D, 2009. Progress in lipid nutrition: The Columbus concept addressing chronic diseases. World Rev. Nutr. Diet., 100: 110-121. PMID: 19696532

Eaton, S.B., M. Konner and M. Shostak 1988. Stone agers in the fast lane: Chronic degenerative diseases in evolutionary perspective. Am. J. Med., 84: 739-749. PMID: 3135745

Eaton, S.B., S.B. Eaton, A.J. Sinclair, L. Cordain and N.J. Mann, 1998. Dietary intake of long-chain polyunsaturated fatty acids during the Paleolithic period. World Rev. Nutr. Diet., 83: 12-23. PMID: 9648501

Eaton, S.B., 2009. Evolution and cholesterol. World Rev. Nutr. Diet., 100: 46-54. DOI: $10.1159 / 000235710$

Endres, S., R. Ghorbani and V.E. Kelley, 1989. The effect of dietary supplementation with n-3 polyunsaturated fatty acids on the synthesis of interleukin-1 and tumor necrosis factor by mononuclear cells. N. Engl. J. Med., 320: 265-271. PMID: 2783477

Esposito, K., R. Marfella, M. Ciotola, C. Di Palo and G. Giugliano et al., 2004. Effect of a Mediterraneanstyle diet on endothelial dysfunction and markers of vascular inflammation in the metabolic syndrome: A randomized trial. JAMA, 292: 14401446. PMID: 15383514
Esposito, K. and D. Glugliano, 2006. Diet and inflammation: A link to metabolic and cardiovascular diseases. Eur. Heart J., 27: 15-20. PMID: 16219650

Fung, T.T., S.E. Chiuve, M.L. McCullough, K.M. Rexrode and G. Logroscino et al., 2008. Adherence to a DASH-style diet and risk of coronary heart disease and stroke in women. Arch. Intern. Med., 168: 713-720. PMID: 18413553

Fung, T.T., V. Malik, K.M. Rexroad, J.E. Manson and W.C. Willett et al., 2009. Sweetened beverage consumption and risk of coronary heart disease in women. Am. J. Clin. Nutr., 89: 1037-1042. PMID: 19211821

Gal, D., D. Pella and R.B. Singh, 2008. The effect of an alpha-linolenic-acid-rich diet on the circadian rhythm of cardiac events. World Heart J., 1: 49-56.

Gramenzi, A., A. Gentile, M. Fasoli, E. Negri and F. Parazzini et al., 1990. Association between certain foods and risk of acute myocardial infarction in women. BMJ, 300: 771-773. PMID: 2322737

Harper, C.R. and T.A. Jacobson, 2005. Usefulness of omega-3 fatty acids and the prevention of coronary heart disease. Am. J. Cardiol., 96: 1521-1529. PMID: 16310434

Harris, W.S., K.J. Reid, S.A. Sands and J.A. Spertus, 2007. Blood omega-3 and trans fatty acids in middle-aged acute coronary syndrome patients. Am. J. Cardiol., 99: 154-158. PMID: 17223410

He, F.J., C.A. Nowson, M. Lucas and G.A. MacGregor, 2007. Increased consumption of fruit and vegetables is related to a reduced risk of coronary heart disease: Meta-analysis of cohort studies. J. Hum. Hypertens., 21: 717-728. PMID: 17443205

Heidemann, C., M.B. Schulze, O.H. Franco, R.M. van Dam and C.S. Mantzoros et al., 2008. Dietary patterns and risk of mortality from cardiovascular disease, cancer and all causes in a prospective cohort of women. Circulation, 118: 230-237. PMID: 18574045

Hsu, L.C., 1974. Commentary-Nutrition-from China to the west art-science quality of nutrition. Ecology Food Nutrition 3: 303-314.

$\mathrm{Hu}$, F.B., 2008. Globalization of food patterns and cardiovascular disease risk. Circulation, 118: 19131914. PMID: 18981311

Iqbal, R., S. Anand, S. Ounpuu, S. Islam and X. Zhang et al., 2008. Dietary patterns and the risk of acute myocardial infarction in 52 countries: Results of the interheart study. Circulation, 118: 1929-1937. PMID: 18936332 
Iso, H., M. Kobayashi, J. Ishihara, S. Sasaki and K. Okada et al., 2006. Intake of fish and n3 fatty acids and risk of coronary heart disease among Japanese: The Japan Public Health Center-Based (JPHC) Study Cohort I. Circulation 113: 195-202. PMID: 16401768

Kang, J.X., J. Wang, L. Wu and Z.B. Kang, 2004. Transgenic mice: Fat-1 mice convert n-6 to n-3 fatty acids. Nature, 427: 504-504. PMID: 14765186

Kartikey, K., G. Singh, B. Kidyore, Y.A. Somsunder and P. Howarth, 2010. Association of dietary w6/w-3 fatty acid ratio and inflammation with risk of hip fracture. Open Nutra. J., 3: 1-5.

Katcher, H.I., R.S. Legro, A.R. Kunselman, P.J. Gillies and L.M. Demers et al., 2008. The effects of a whole grain-enriched hypocaloric diet on cardiovascular disease risk factors in men and women with metabolic syndrome. Am. J. Clin. Nutr., 87: 79-90. PMID: 18175740

Bhishagratna, K.K.L., 2006. The Sushruta Samhita: An English Translation Based on Original Texts. 1st Edn., Cosmo Publications, Nasik, India., ISBN-10: 8130702770, pp: 2000

Knoops, K.T.B., L.C.P.G.M. de Groot, D. Kromhout, A.E. Perrin and O. Moreiras-Varela et al., 2004. Mediterranean diet, lifestyle factors and 10-year mortality in elderly European men and women. The HALE project. JAMA, 292: 1433-1439. PMID: 15383513

Kumar, S.G., U.N. Das, K.V. Kumar, N. Madhavi and N.P. Das et al., 1992. Effect of n-6 and n-3 fatty acids on the proliferation of human lymphocytes and their secretion of TNF- $\alpha$ and IL-2 in vitro. Nutr. Res., 12: 815-823. DOI: 10.1016/S02715317(05)80639-6

McCall, D.O., C.P. McGartland, M.C. McKinley, C.P. Patterson and P. Sharpe et al., 2009. Dietary Intake of Fruits and Vegetables Improves Microvascular Function in Hypertensive Subjects in a DoseDependent Manner. Circulation, 119: 2153-2160. PMID: 19364976

McLennan, P.L., M.Y. Abeywardena and J.S. Charnock, 1988. Dietary fish oil prevents ventricular fibrillation following coronary artery occlusion and reperfusion. Am. Heart J., 16: 709716. PMID: 3414486

Pella, D., G. Dubnov, R.B. Singh, R. Sharma and E.M. Berry et al., 2003. Effects of an IndoMediterranean diet on the omega-6/omega-3 ratio in patients at high risk of coronary artery disease: The Indian paradox. World Rev. Nutr. Diet., 92: 74-80. PMID: 14579684
Renaud, S., M. de Lorgeril, J. Delaye, J. Guidollet and F. Jacquard et al., 1995. Cretan mediterranean diet for prevention of coronary heart disease. Am. J. Clin. Nutr., 61: 1360S-1367S. PMID: 7754988

Simopoulos, AP., 1994. Is Insulin Resistance Influenced by dietary linoleic acid and trans fatty acids. Free Radical Biol. Med., 17: 367-372. PMID: 8001841

Simopoulos, A., 1999. Essential fatty acids in health and chronic disease. Am. J. Clin. Nutr., 70: 560S569S. PMID: 10479232

Simopoulos, A.P., 2003. Importance of the ratio of omega-6/omega-3 essential fatty acids: evolutionary aspects. World Rev. Nutr. Diet., 92: 1-22. PMID: 14579680

Simopoulos, A.P., 2006. Evolutionary aspects of diet, the omega-6/omega-3 ratio and genetic variation: Nutritional implications for chronic diseases. Biomed. Pharmacol, 60: 502-507. PMID: 17045449

Simopoulos, A.P., 2008. The importance of the omega6/omega-3 fatty acid ratio in cardiovascular disease and other chronic diseases. Exp. Biol. Med., 233: 674-688. PMID: 18408140

Simopoulos, A.P., 2009. Evolutionary aspects of the dietary omega-6:omega-3 fatty acid ratio: medical implications. World Rev. Nutr. Diet, 100: 1-21. PMID: 19696523

Singh, R.B., S.S. Rastogi, M.A. S. Niaz and R.G. Singh, 1992a. Effect of fat-modified and fruit- and vegetable-enriched diets on blood lipids in the Indian diet heart study. Am. J. Cardiol, 69: 869874. PMID: 1529939

Singh, R.B., S.S. Rastogi, R. Verma, L. Bolaki and R. Singh, 1992b. An Indian experiment with nutritional modulation in acute myocardial infarction. Am. J. Cardiol., 69: 879-85. PMID: 1550016

Singh, R.B., S.S. Rastogi, R. Verma, B. Laxmi and R. Singh et al., 1992c. Randomised controlled trial of cardioprotective diet in patients with recent acute myocardial infarction: Results of one year follow up. BMJ, 304: 1015-1019. PMID: 1586782

Singh, R.B., M.A. N. Agarwal, P, Beegum and R. Rastogi, 1995. Effect of antioxidant rich foods on plasma ascorbic acid, cardiac enzyme and lipid peroxide levels in patients hospitalized with acute myocardial infarction. J. Am. Diet. Assoc., 95: 775-780. PMID: 7797808 
Singh, R.B., M.A. Niaz, S. Ghosh, R. Beegom and V. Rastogi et al., 1996. Association of trans fatty acids (vegetable ghee) and clarified butter (Indian ghee) intake with higher risk of coronary artery disease in rural and urban populations with low fat consumption. Int. J. Cardiol., 56: 299-300. PMID: 8910075

Singh, R.B., M.A. Niaz, R. Beegom, G.S. Wander and A.S. Thakur et al., 1999. Body fat percent by bioelectrical impedance analysis and risk of coronary artery disease among urban men with low rates of obesity: The Indian paradox. J. Am. Coll. Nutr., 18: 268-273. PMID: 10376784

Singh, R.B., R. Beegom, S.P. Verma, M. Haque and R. Singh et al., 2000. Association of dietary factors and other coronary risk factors with social class in women in five Indian cities. Asia Pac. J. Clin. Nutr., 9: 298-302.

Singh, R.B., G. Dubnov, M.A. Niaz, S. Ghosh and R. Singh et al., 2002. Effect of an Indo-Mediterranean diet on progression of coronary artery disease in high risk patients (Indo-mediterranean diet heart study): A randomised single-blind trial. Lancet, 360: 1455-1461. PMID: 12433513

Singh, R.B., D. Pella and F.De Meester, 2006. What to 'eat and chew' in acute myocardial infarction?. Eur. Heart J., 27: 1628-1629. PMID: 16717073

Singh, R.B., F. De Meester, V. Mechirova, D. Pella and K. Otsuka, 2008. Fatty acids in the causation and therapy of metabolic syndrome. In Wild Type Foods in Health Promotion and Disease Prevention, Meester, F.D. and R.R. Watson, (Eds.)., Humana Press, NJ pp: 263-284.

Singh, R.B., F. De Meester, D. Pella, T.K. Basu and R. Watson, 2009. Globalization of dietary wild foods protect against cardiovascular disease and all cause mortalities? A scientific statement from the international college of cardiology, columbus paradigm institute and the international college of nutrition. Open Nutraceuticals J., 2: 42-45.

Singh, R.B., F. De Meester, A. Wilczynska, D.W. Wilson and A.P.S. Hungin, 2010. The liverpancreas and brain connection in the pathogenesis of obesity and diabetes mellitus. World Heart J., 2: 319-326.

Singh, R.B., S. Dharwadkar, F. De Meester, L. Juneja and D. Pella, 2011d. Role of cardioprotective diet in acute coronary syndrome. Am. Med., J. 2: 98103. DOI: 10.3844/amjsp.2011.98.103

Singh, R.B., J. Fedacko, D. Pella, Z. Macejova and S. Ghosh et al., 2011a. Prevalence and risk factors for prehypertension and hypertension in five Indian cities. Acta Cardiol., 66: 29-37. PMID: 21465750
Singh, R.B., J. Fedacko, V. Vargova, M.A. Niaz and S.S. Rastogi et al., 2012. Effect of low W-6/W-3 ratio fatty acid Paleolithic style diet in patients with acute coronary syndromes. A randomized, single blind, controlled trial. World Heart J.

Singh, R.B., M. Moshiri, F. De Meester, L. Juneja and V. Muthusamy et al., 2011b. The Evolution of low w-6/w-3 ratio dietary pattern and risk of cardiovascular disease and diabetes mellitus. J. Altern. Med. Res., 3: 45-70.

Singh, R.B., K.K. Reddy, J. Fedacko, F. De Meester and A. Wilczynska et al., 2011c. Ancient Concepts of Nutrition and the Diet in Hunter-gatherers. Open Nutra. J., 4: 130-135.

Sofi, F., R. Abbate, G.F. Gensini and A. Casini 2010. Accruing evidence on benefits of adherence to the Mediterranean diet on health: an updated systematic review and meta-analysis. Am. J. Clin. Nutr., 92: 1189-1196. PMID: 20810976

Takahashi, T., E. Toda, R.B. Singh, A.K. Singh and F. De Meester et al., 2012. Nutrient and the mindbody axis, in relation to omega-3 fatty acids and amino acids. Am. Med. J., 3: 14-26. DOI: 10.3844/amjsp.2012.14.26

Trichopoulou, A., T. Costacou, C. Bamia and D. Trichopoulos, 2003. Adherence to a Mediterranean diet and survival in a Greek population. N. Engl. J. Med., 348: 2599-2608. PMID: 15521707

Vogel, R.A., 2006. Eating, vascular biology and atherosclerosis: A lot to chew on. Eur. Heart J., 27: 13-14. PMID: 16272214

Wang, P.Y., L. Caspi, C.K. Lam, M. Chari and X. Li et al., 2008. Upper intestinal lipids trigger a gutbrain-liver axis to regulate glucose production. Nature, 452: 1012-1016. PMID: 18401341

Wilson, D.W., A.P.S. Hungin, J.H. Howse, F.D. Meester and Singh et al., 2011. Role of hormones and neuropeptides in IBS and other gastrointestinal disorders: Understanding variability and chrononutrition. Open Nutraceuticals J., 4: 213225.

Zhang, L., D. Hou, X. Chen, D. Li and L. Zhu et al., 2011. Exogenous plant MIR168a specifically targets mammalian LDLRAP1: evidence of crosskingdom regulation by microRNA. Cell Res., PMID: 21931358 